\title{
Impacto do desempenho hidroenergético de sistema de abastecimento de água no consumo de energia elétrica em campus universitário
}

\author{
Impact of the hydroenergetic performance of the water supply \\ system in the electric energy consumption in the university campus
}

\author{
Data de entrada: \\ $11 / 04 / 2017$ \\ Data de aprovação: \\ $23 / 07 / 2018$
}

Jorge Fernando Hungria Ferreira' ${ }^{1 *}$ | Raynner Menezes Lopes ${ }^{1}$ | José Almir Rodrigues Pereira1

DOI: https://doi.org/10.36659/dae.2020.019

ORCID ID

Ferreira,J.F.H (D) https://orcid.org/0000-0002-6653-4633
Lopes, R.M (D) https://orcid.org/0000-0002-1704-4152

Pereira, J.A.R (DD https://orcid.org/0000-0002-3144-1787

\section{Resumo}

Nesse trabalho foi analisada a operação de quatro Estações Elevatória de Água (EEA), tendo como objetivo verificar o impacto no consumo e na despesa de energia elétrica do Sistema de Abastecimento de Água (SAA) da Cidade Universitária Professor José da Silveira Netto, campus principal da Universidade Federal do Pará (UFPA). Para isso, foram realizadas atividades em três etapas, sendo na primeira monitorados parâmetros hidráulicos e elétricos nas quatro EEAs, em intervalos de 10s, durante 24h. Em seguida, os 103.680 dados monitorados foram sistematizados, possibilitando o cálculo de indicadores de desempenho hidroenergético. Na última etapa foram analisados o consumo e a despesa de energia elétrica nas quatro EEAs. Os resultados obtidos demonstraram que as EEAs não tiveram a operação paralisada durante o horário de ponta e que houve consumo de energia elétrica reativa excedente devido aos baixos valores de fator de potência. $O$ consumo específico de energia elétrica agregada foi de $0,52 \mathrm{kWh} / \mathrm{m}^{3}$ na Linha $1 \mathrm{com}$ as Elevatórias de Água Bruta (EEAB) e de Água Tratada 1 (EEAT 1), e de 0,47 kWh/m $\mathrm{m}^{3}$ na Linha 2 com as elevatórias EEAB, EEAT 2 e EEAT 3. Isso resultou nos custos de energia elétrica no horário de ponta de $1,89 \mathrm{R} \$ / \mathrm{m}^{3}$ na Linha 1 e de $1,71 \mathrm{R} \$ / \mathrm{m}^{3}$ na Linha 2, sendo no horário fora de ponta observados valores de $0,27 \mathrm{R} \$ / \mathrm{m}^{3}$ e $0,24 \mathrm{R} \$ / \mathrm{m}^{3}$, respectivamente. Na pesquisa foi constatada a necessidade de modificação do desempenho operacional das EEAs para reduzir o bombeamento de água no período noturno e no horário de ponta, o que, naturalmente, diminuirá os valores verificados de consumo $(50.705 \mathrm{kWh} /$ mês) e de despesa de energia elétrica ( $R \$ 46.548,00$ por mês) no SAA do campus.

Palavras-chave: Bombeamento de água. Energia elétrica. Despesa.

\section{Abstract}

In this paper, the operation of four Water Pumping Stations (WPS) was analyzed to verify the impact on electric energy consumption and cost of the Water Supply System (WSS) of the University City Professor José da Silveira Netto, main campus of the Federal University of Pará (UFPA). For this, activities were performed in three stages; in the first stage, the hydraulic and electrical parameters in the four WPSs were monitored in intervals of 10s during

\footnotetext{
${ }^{1}$ Universidade Federal do Pará - Laboratório de Eficiência Energética e Hidráulica no Saneamento - LENHS/UFPA. Belém - PA - Brasil.

*Autor correspondente: fernandohughes13ahotmail.com.
} 
24h. Then, the 103,680 data was systematized, allowing the calculation of hydroenergetic performance indicators. In the last stage, the electricity consumption and expenditure in the four WPSs were analyzed. The results obtained showed that the WPSs were not paralyzed during peak time and that there was excess reactive energy consumption due to the low power factor. The specific consumption of aggregate electric energy was $0.52 \mathrm{kWh} / \mathrm{m}^{3}$ in Line 1 with the Raw Water Pump Station (RWPS) and Treated Water Pumping Station 1 (TWPS 1), and $0.47 \mathrm{kWh} / \mathrm{m}^{3}$ in Line 2 with RWPS, TWPS 2 and TWPS 3. This resulted in peak electricity costs of $R \$ 1.89 / \mathrm{m}^{3}$ in Line 1 and $R \$ 1.71 R \$ / \mathrm{m}^{3}$ in Line 2, and in the off-peak time, values of $R \$ 0.27 / \mathrm{m}^{3}$ and $0.24 R \$ / \mathrm{m}^{3}$, respectively. Finally, it was verified the need to modify the operational performance, to reduce the pumping of water at night and in peak times, which will reduce the verified values of electric energy consumption (50,705 $\mathrm{kWh} / \mathrm{month})$ and cost ( $R \$ 46,548.00$ per month) in the SAA of the campus.

Keywords: Water pumping. Electricity. Costs.

\section{INTRODUÇÃO}

Os esforços requeridos na relação homem-natureza para o uso adequado e não extrapolado dos bens presentes no meio e disponíveis à humanidade, dentre os quais podem ser destacados a água e a energia, são de grande importância para a viabilização e a manutenção da vida contemporânea. Para Cavalcanti (2012), essa relação deve ocorrer de forma sustentável, munida de processo socioeconômico em que se minimize o uso de matéria e energia, bem como os impactos ambientais provenientes da ação antrópica, e que se maximize a eficiência do uso dos recursos e sua utilidade social.

Os recursos hídricos e energéticos são intrínsecos ao setor de saneamento. Cerca de 3\% da energia elétrica gerada no Brasil são consumidos no setor de abastecimento de água e no tratamento de esgoto (GONÇALVES, JORDÃO, JANUZZI, 2009). Segundo o Sistema Nacional de Informações Sobre Saneamento (SNIS), $11 \mathrm{mi}$ Ihões de MWh/ano são utilizados em Sistemas de Abastecimento de Água (SAA) e 1,2 milhão MWh/ano em esgotamento sanitário (BRASIL, 2017). Vale observar que cerca de $90 \%$ da energia utilizada no SAA são consumidos nos Conjuntos Motor e Bomba (CMB) (GOMES, 2012; BRANDT et al., 2011).
De acordo com a Environmental Protection Agency - EPA (2017), até $40 \%$ dos custos operacionais para SAA podem ser relativos ao consumo de energia. Além disso, Barry (2007) ressalta que o consumo de energia elétrica corresponde a $74 \%$ do investimento realizado ao longo da vida útil de instalações de bombeamento. Luz et al. (2016) comentam que o consumo demasiado de energia em Estações Elevatórias de Água (EEA) deve-se, muitas vezes, aos equipamentos obsoletos e não dimensionados conforme a necessidade.

Além disso, outros fatores influenciam na despesa de energia elétrica, como o baixo valor do fator de potência, que é relacionado ao consumo e à demanda de energia elétrica reativa excedente, o bombeamento no horário de ponta do setor elétrico, que é o período de três horas consecutivas em que o valor da tarifa de energia elétrica é maior do que o cobrado nas demais horas do dia, e o volume perdido de água entre as unidades de captação e de distribuição de água. Zhuan et al. (2018) citam como ação para redução de despesa de energia elétrica o desligamento dos CMBs nos horários de ponta. Segundo Tang, Zheng e Zhang (2014), uma economia de quase $30 \%$ na despesa de energia para o bombeamento de água pode ser alcançada com o controle ótimo no deslocamento do horário de operação dos CMBs. 
As despesas decorrentes de operação deficiente dos SAAs, aliadas aos volumes de água perdidos, os quais não serão faturados, podem comprometer a sustentabilidade econômica dos SAAs. De acordo com Brasil (2017), as prestadoras brasileiras de serviço de abastecimento de água deixaram de faturar no ano de 2015, em média, $34,8 \%$ do volume de água produzido, sendo que na região Norte do país esse valor foi de $55,3 \%$.

Santos e Pereira (2016) comentam que esses elevados percentuais indicam problemas na gestão dos SAAs, como ligações clandestinas, uso excessivo de água na limpeza das unidades do sistema e vazamentos em redes de distribuição e em adutoras de água. Rego et al. (2015) recomendaram, em sua pesquisa, análise da demanda real e redução das perdas de água para subsidiar meIhorias operacionais no setor de abastecimento de água estudado. Stavenhagen, Buurman e Tortajada (2018) classificaram as ações de renovação e manutenção da rede de distribuição e de campanhas de tecnologia de economia de água como as ações de maior impacto na gestão da demanda de água das cidades participantes da sua pesquisa.

Além disso, o volume de água desperdiçado no SAA possui agregado o valor da energia elétrica consumida para o seu deslocamento em todas as EEAs instaladas a montante no SAA (PEREIRA; CONDURÚ, 2014; SANTOS, 2015). Bezerra e Cheung (2013) comentam que a perda de água em SAA resulta em desperdício da energia utilizada em todos os processos do sistema.

Nesse sentido, as perdas de água, além de ocasionar redução no faturamento das prestadoras de serviço de abastecimento de água, também estão relacionadas com as despesas de ener- gia elétrica dos SAA. Brasil (2017) verificou que a despesa com energia elétrica de $\mathrm{R} \$ 5.136,2$ milhões correspondeu a $15,6 \%$ da despesa de exploração (DEX) das prestadoras de serviço de água e esgoto participantes da pesquisa.

No entanto, a preocupação com os elevados valores de consumo e de despesa de energia elétrica nos SAAs é antiga no Governo Federal. Em 2003, a Eletrobrás instituiu o Programa de Eficiência Energética em Saneamento Ambiental (PROCEL SANEAR), com o objetivo de promover o uso eficiente de energia elétrica e água em sistemas de saneamento ambiental, incentivar o uso eficiente dos recursos hídricos como estratégia de prevenção à escassez de água destinada à geração hidroelétrica e contribuir para a universalização dos serviços de saneamento ambiental (PROCEL INFO, 2006).

Contudo, o grande desperdício de energia elétrica nos SAAs ainda ameaça a sustentabilidade econômico-financeira da prestação de serviços de abastecimento de água. Nesse contexto, o objetivo do presente trabalho foi analisar as condições operacionais do SAA do campus da UFPA, apontando deficiências hidroenergéticas que afetam o desempenho dos CMBs e impactam no consumo e na despesa de energia elétrica no bombeamento de água.

\section{METODOLOGIA}

A pesquisa foi realizada nas quatro EEAs do SAA da Cidade Universitária Professor José da Silveira Netto, campus principal da Universidade Federal do Pará (UFPA), localizado no município de Belém, estado do Pará, conforme representado na Fig. 1. 
Figura 1 - Mapa de localização do campus da UFPA e a divisão dos setores

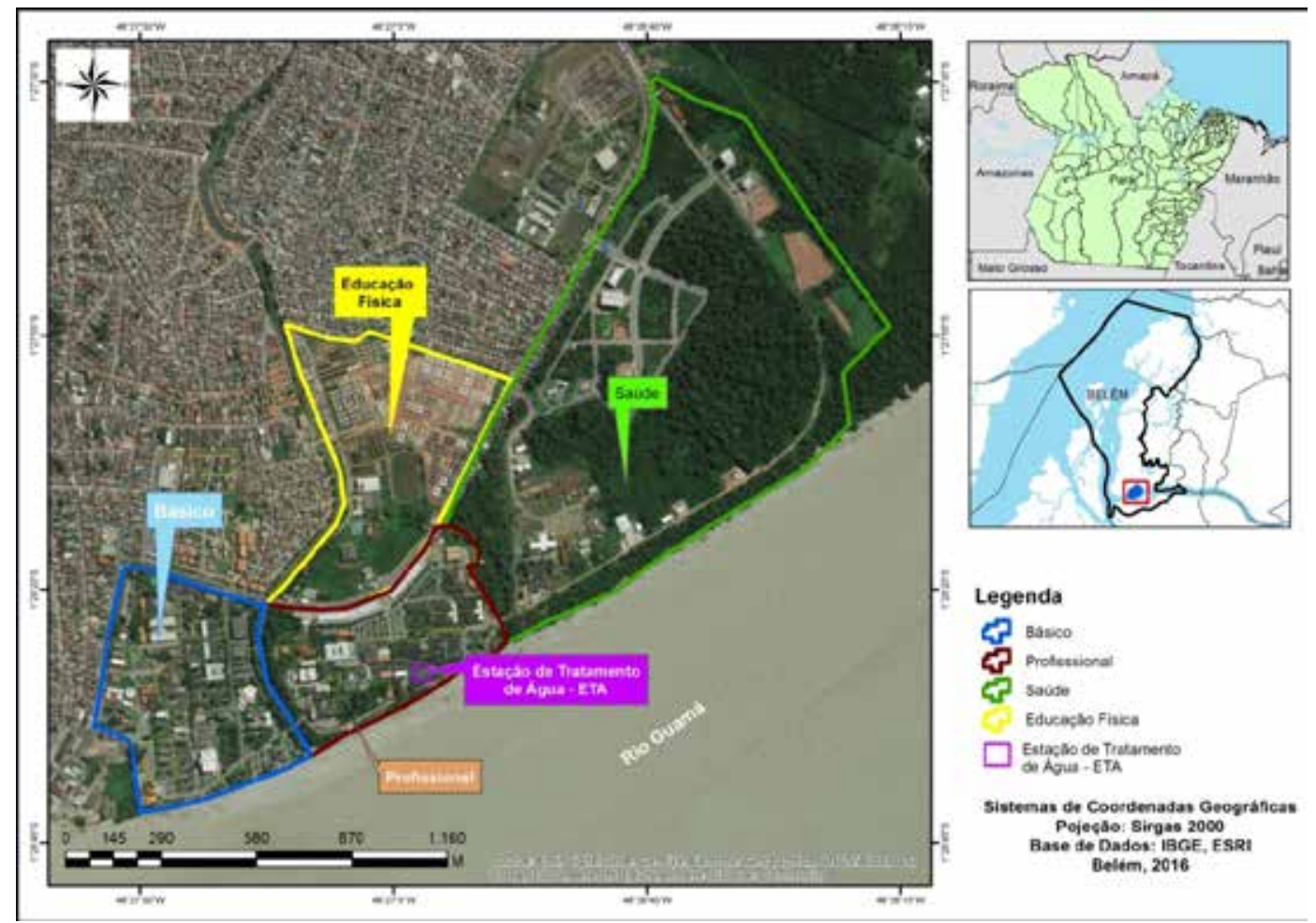

O funcionamento do campus ocorre das $07 \mathrm{~h}$ às $21 \mathrm{~h}$ horas, para atender a uma população flutuante de professores, técnicos, alunos (graduação e pós-graduação) e visitantes. Segundo a UFPA (2017), o campus contava com 21.320 alunos de graduação matriculados no ano de 2016. No SAA do campus, a água bruta é captada em poço artesiano de 250 metros de profundidade, sendo bombeada para a Estação de Tratamento de Água (ETA) e, então, distribuída aos Setores Básico, Profissional, Saúde e Educação Física.

O SAA é constituído por quatro pontos de bombeamento de água, no caso a Estação Elevatória de Água Bruta (EEAB) de poço profundo, e três Estações Elevatórias de Água Tratada (EEAT), que bombeiam a água para o reservatório elevado do setor profissional (EEAT 1), para o reservatório enterrado do setor básico (EEAT 2) e para o reservatório elevado do setor básico (EEAT 3).

O SAA possui dois reservatórios enterrados, de volume total de $180 \mathrm{~m}^{3}$ cada um, e dois reservatórios elevados de volume total de $120 \mathrm{~m}^{3}$ cada um. Na Fig. 2 é representada a configuração do SAA, sendo oportuno citar que a UFPA não dispõe de cadastro atualizado da rede de distribuição de água. 
Figura 2 - Configuração do SAA do campus universitário

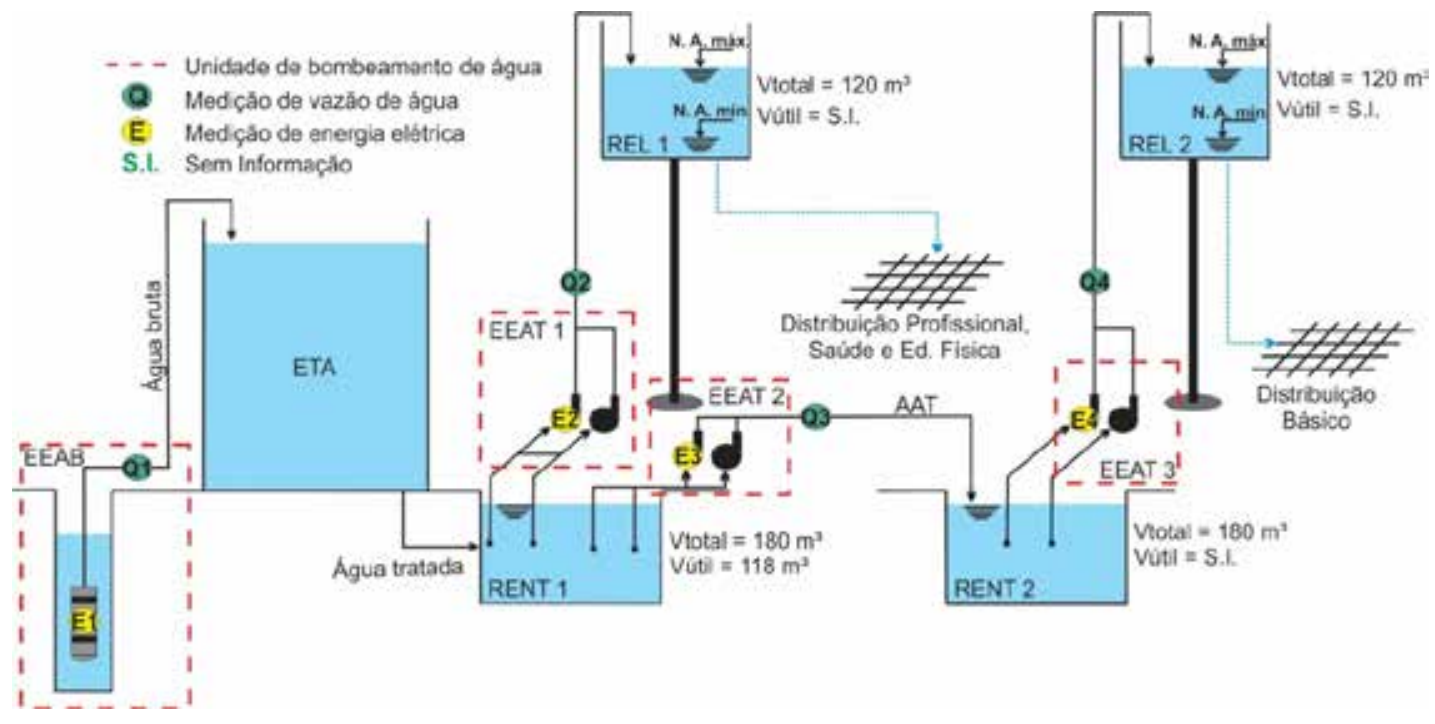

Vale observar que as operações das EEAs, no período da pesquisa, ocorreram nas configurações 1+2 para a EEAB e 1+1 para as EEAT 1, EEAT 2 e EEAT 3. Na Tabela 1 são apresentadas algumas informações das instalações das EEAs.

Tabela 1 - Características das EEAs

\begin{tabular}{|c|c|c|c|c|c|c|c|c|}
\hline \multirow{2}{*}{$\begin{array}{l}\text { Estação } \\
\text { elevatória }\end{array}$} & \multirow{2}{*}{$\begin{array}{l}\text { Potência do } \\
\text { motor (CV) }\end{array}$} & \multicolumn{3}{|c|}{ Diâmetro da tubulação (mm) / Material } & \multicolumn{3}{|c|}{ Comprimento da tubulação (m) } & \multirow{2}{*}{$\begin{array}{c}\mathrm{H}_{\text {geo. }}{ }^{1} \\
\text { (m) }\end{array}$} \\
\hline & & Suc. & Bar. & Rec. & Suc. & Bar. & Rec. & \\
\hline EEAB & 60 & $\begin{array}{l}- \\
-\end{array}$ & - & $\begin{array}{c}300 ; 200 ; 125 \\
-\end{array}$ & - & - & $80 ; 170 ; 36$ & - \\
\hline EEAT 1 & 20 & $\begin{array}{l}150 \\
\text { F. F. }^{2}\end{array}$ & $\begin{array}{l}100 \\
\text { F. F. }\end{array}$ & $\begin{array}{l}150 \\
\text { PVC }^{3}\end{array}$ & 4,9 & 0,58 & 41,2 & 18,6 \\
\hline EEAT 2 & 10 & $\begin{array}{l}150 \\
\text { F. F. }\end{array}$ & $\begin{array}{l}125 \\
\text { F. F. }\end{array}$ & $\begin{array}{l}200 \\
\text { PVC }\end{array}$ & 5,27 & 1,7 & 1.180 & 1,0 \\
\hline EEAT 3 & 15 & $\begin{array}{l}150 \\
\text { F. F. }\end{array}$ & $\begin{array}{l}125 \\
\text { F. F. }\end{array}$ & $\begin{array}{l}125 \\
\text { F.F. }\end{array}$ & 5,55 & 2,52 & 21,6 & 17,0 \\
\hline
\end{tabular}

${ }^{1}$ Altura geométrica. ${ }^{2}$ Ferro fundido. ${ }^{3}$ Policloreto de vinila.

Essas informações foram utilizadas para o desenvolvimento da pesquisa, que foi realizada em três etapas, conforme apresentado na Fig. 3.

Figura 3 - Etapas da pesquisa

Etapa 1: Monitoramento dos parâmetros hidráulicos e elétricos das EEAs

- Monitoramento em campo dos parâmetros hidráulicos e elétricos das EEAs;

- Tratamento e sistematização dos dados aquisitados.

\section{Etapa 2: Análise do desempenho hidroenergético das EEAs}

- Cálculo de indicadores de desempenho hidroenergético;

- Análise dos indicadores hidroenergéticos.

\section{Etapa 3:Análise do consumo e da despesa de energia elétrica do SAA}

- Identificação do enquadramento tarifário do SAA;

-Estimativa do impacto da despesa de energia elétrica do SAA na despesa de energia elétrica do campus;

-Avaliação de possíveis reduções na despesa de energia elétrica do SAA. 


\subsection{Etapa 1 - Monitoramento dos parâmetros hidráulicos e elétricos}

Na primeira etapa foi realizado o monitoramento da vazão de bombeamento de água e do consumo de energia elétrica nas quatro EEAs do campus. O monitoramento ocorreu em dias diferentes em função da disponibilidade dos equipamentos.

No monitoramento da vazão de água bombeada, foram utilizados equipamentos ultrassônicos portáteis, não intrusivos, de precisão de 0,5\%+em relação ao fundo de escala. Esses equipamentos foram instalados nas tubulações de recalque de cada EEA nos pontos de monitoramento Q1, Q2, Q3 e Q4, conforme representados na Fig. 2.

Por sua vez, as grandezas elétricas foram monitoradas por equipamentos analisadores de qualidade de energia elétrica com sistema de precisão de 0,2\%+-. Esses equipamentos foram instalados nos quadros elétricos dos pontos de monitoramento do setor profissional (QEP) e do setor básico (QEB), possibilitando a medição de grandezas elétricas na operação dos CMBs representados por E1, E2, E3 e E4 (Fig. 2). Vale citar que no ponto de monitoramento QEP foram realizadas as medições dos parâmetros elétricos da EEAB, EEAT 1 e EEAT 2; e no QEEB foi realizada medição dos parâmetros apenas da EEAT 3.

O monitoramento foi realizado nos meses de setembro e outubro do ano de 2016, com os equipamentos instalados em período de 24 horas e intervalo de 10 segundos entre os armazenamentos dos parâmetros medidos. Com isso, foram registrados 8.640 dados de vazão de água, 8.640 de potência ativa e 8.640 de fator de potência em cada uma das quatro EEAs, totalizando 103.680 dados monitorados. Os dados registrados no monitoramento foram analisados para verificação de possíveis erros e interferências de leitura dos equipamentos. Posteriormente, os dados foram tratados e sistematizados em tabelas e gráficos para serem utilizados nas Etapas 2 e 3.
As tabelas e os gráficos foram elaborados com a finalidade de facilitar a identificação de variações no comportamento do volume de água bombeado nos horários de ponta (das $18 \mathrm{~h}$ às $21 \mathrm{~h}$ ) e fora de ponta (das $21 \mathrm{~h}$ às $18 \mathrm{~h}$ ), observando, ainda, os valores de volumes de água bombeados em quatro diferentes períodos do dia, no caso de $0 \mathrm{~h}$ às $6 \mathrm{~h}$, das $6 \mathrm{~h}$ às $12 \mathrm{~h}$, das $12 \mathrm{~h}$ às $18 \mathrm{~h}$ e das $18 \mathrm{~h}$ às $24 \mathrm{~h}$. Nas quatro EEAs também foram identificados os números de acionamento, os períodos médios de funcionamento por acionamento, as horas de funcionamento diário e os percentuais de tempo diário de funcionamento dos CMBs das EEAs.

A sistematização dos dados de energia elétrica possibilitou a identificação da variação do consumo de energia elétrica e a quantificação dos valores de consumo médio horário, diário e mensal estimado nos horários de ponta e fora de ponta, bem como a quantificação da variação do consumo horário de energia elétrica ao longo do dia. Também foi possível comparar os valores dos fatores de potência dos CMBs das EEAs especificados nos equipamentos e os registrados no monitoramento.

\subsection{Etapa 2: Análise do desempenho hidroenergético das EEAs}

$\mathrm{Na}$ segunda etapa, foram utilizados indicadores para possibilitar a análise do desempenho hidroenergético das EEAs do SAA do campus universitário. Inicialmente foi calculado o Consumo Específico de Energia Elétrica (CEE, em $\mathrm{kWh} / \mathrm{m}^{3}$ ), que é a razão entre a energia elétrica consumida (EEC, em $\mathrm{kWh}$ ) e o volume bombeado (VB, em $\mathrm{m}^{3}$ ), conforme mostrado na Eq. 1.

$\mathrm{CEE}=\frac{\mathrm{EEC}}{\mathrm{V}_{\mathrm{B}}}$ Eq. 1

Em seguida, foi calculado o Consumo Específico Normalizado (CEEN, em $\mathrm{kWh} / \mathrm{m}^{3} / 100 \mathrm{~m}$ ), que é de- 
finido como a energia elétrica necessária para uma EEA recalcar a cem metros de altura manométrica (Hman, em m) um metro cúbico de água (Eq. 2).

$$
\mathrm{CEEN}=\frac{\mathrm{EEC}}{\mathrm{V}_{\mathrm{B}} \cdot\left(\frac{\mathrm{Hman}}{100}\right)}
$$

Os valores das alturas manométricas das EEAs foram determinados utilizando a Eq. 3, adaptada da fórmula de perda de carga de Hazen-Williams. Em cada EEA foram verificadas as alturas geométricas $(\mathrm{Hg}$, em $\mathrm{m}$ ) e calculados os valores das perdas de carga ao longo da tubulação e os valores das perdas localizadas, considerando o comprimento de tubulação equivalente a essas perdas.

Para isso, foram levadas em consideração as características dos sistemas hidráulicos das EEAs, como comprimento das tubulações ( $L$, em $m$ ), diâmetros ( $D$, em $m)$, conexões e outras singularidades, e adotado coeficiente $\mathrm{C}$ da fórmula de Hazen-Williams para tubulações com mais ou menos dez anos de uso, no caso utilizando os valores recomendados por Azevedo Netto (2015) de $C$ igual a 130 para tubulação de ferro fundido dúctil com revestimento permanente, e de 137,5 para tubulação de PVC, ambos os valores de C para tubulações com diâmetros entre $125 \mathrm{~mm}$ e $550 \mathrm{~mm}$. Também foram considerados para os cálculos os valores monitorados de vazão máxima de bombeamento de água $\left(\mathrm{Q}, \mathrm{em} \mathrm{m}^{3} / \mathrm{s}\right)$.

Hman $=H g+\sum\left(\operatorname{Lx} 10,643 \times \frac{Q^{1,85}}{C^{1,85} \times D^{4,87}}\right)$ Eq.3

Vale observar que, devido ao desconhecimento da altura geométrica da EEAB, o valor de CEEN dessa unidade de bombeamento não foi calculado. Os resultados dos indicadores de desempenho foram comparados para a avaliação da eficiência hidroenergética nas EEAs do SAA. Os resultados do CEEN também foram avaliados em função do valor comentado por Alegre et al. (2006) no caso CEEN de $0,5 \mathrm{kWh} / \mathrm{m}^{3}$.

Também foram calculados os valores de CEE dos volumes de água distribuídos nos setores do campus levando em consideração o consumo agregado de energia elétrica em todas as EEAs instaladas a montante das redes de distribuição. Para isso, foram consideradas duas linhas de fluxo de água no SAA, a Linha 1 contendo a EEAB e a EEAT 1 , cujo volume de água é distribuído aos Setores Profissional, Saúde e Educação Física, e a Linha 2 contendo a EEAB, a EEAT 2 e a EEAT 3, cujo volume de água é distribuído ao Setor Básico.

\subsection{Etapa 3: Análise do consumo e da despesa de energia elétrica do SAA}

Na terceira etapa foram identificados os critérios de tarifação aplicados ao SAA do campus, calculada a despesa de energia elétrica com os dados do monitoramento, avaliado o impacto do consumo de energia elétrica do SAA na despesa total de energia elétrica do campus universitário e verificado o potencial de redução da despesa de energia elétrica do SAA com o deslocamento da energia consumida no horário de ponta para o horário fora de ponta.

Para isso, foram levantadas informações nas faturas encaminhadas pela concessionária de energia elétrica, Centrais Elétricas do Pará (CELPA), ao campus universitário, no caso, as faturas de energia elétrica dos meses de junho e julho de 2017. Também foi identificada a modalidade tarifária aplicada para cobrança do consumo e da demanda de energia elétrica da unidade consumidora do campus.

Em seguida, foi aplicada a metodologia proposta por Gomes (2012, p. 439) para calcular a despesa de energia elétrica utilizando os dados monitorados, o que possibilitou quantificar o valor da fatura de energia elétrica $(V F$, em $R \$$ ) referente ao SAA. Nessa atividade, foi empregada a Eq. 4. 


$$
\mathrm{VF}=[(\mathrm{FC}+\mathrm{FD}+\mathrm{FER}+\mathrm{FDR}) *(1-\mathrm{desc})+\mathrm{FU}] *\left(\frac{1}{1-\mathrm{ICMS}}\right)+\text { outros }
$$

Para o cálculo do valor da fatura de energia elétrica ativa ( $F C$, em $\mathrm{R} \$$ ), foram utilizados os valores de consumo de energia elétrica ativa (CE, em kWh) e os valores da tarifa de consumo de energia ativa (TC, em $R \$ / k W h$ ) dos horários de ponta e fora de ponta, sendo empregada a Eq. 5.

$$
\mathrm{FC}=\mathrm{CE}_{\mathrm{p}} * \mathrm{TC}_{\mathrm{p}}+\mathrm{CE}_{\mathrm{fp}} * \mathrm{TC}_{\mathrm{fp}} \quad \text { Eq. } 5
$$

A Eq. 6 foi utilizada para calcular o valor faturado de demanda ativa (FD, em R\$), levando em consideração os valores de demanda de energia elétrica ativa contratada (DC, em kW) e os valores tarifários de demanda de energia elétrica ativa (TD, em R\$/kW).

$$
\mathrm{FD}=\mathrm{DC} * \mathrm{TD}
$$

Eq. 6

O valor faturado do consumo de energia elétrica reativa excedente (FER, em $R \$$ ) foi calculado com a Eq. 7, sendo observados os valores de consumo de energia elétrica ativa (CE, em kWh), fator de potência de referência ( $\mathrm{fr}$, adimensional), fator de potência da instalação elétrica (ft, adimensional) e os valores da tarifa de consumo de energia elétrica ativa ( $T C$, em $\mathrm{R} \$ / \mathrm{kWh}$ ) dos horários de ponta e fora de ponta.

$\mathrm{FER}=\mathrm{CE} *\left(\frac{\mathrm{f}_{\mathrm{r}}}{\mathrm{f}_{\mathrm{t}}}-1\right) * \mathrm{TC}$

No cálculo do valor faturado de demanda de energia elétrica reativa excedente (FDR, em $\mathrm{R} \$$ ), foram utilizados os valores de demanda de energia elétrica ativa monitorada (DM, em kW), de demanda de energia elétrica ativa contratada (DC, em kW), fator de potência de referência ( $\mathrm{fr}$, adimensional), fator de potência da instalação elétrica (ft, adimensional) e o valor tarifário de demanda de energia elétrica ativa (TD, em $\mathrm{R} \$ / \mathrm{kW}$ ). Para isso, foi utilizada a Eq. 8.

$$
\mathrm{FDR}=\left[\left(\mathrm{DM} * \frac{\mathrm{f}_{\mathrm{r}}}{\mathrm{f}_{\mathrm{t}}}\right)-\mathrm{DC}\right] * \mathrm{TD}
$$

Com a Eq. 9 é possível calcular o valor faturado de demanda de ultrapassagem, considerando os valores de demanda de ultrapassagem de energia elétrica faturável (DUF, em kW) e da tarifa de ultrapassagem faturável de demanda de energia elétrica (TUD, em $R \$ / k W$ ).

$$
\mathrm{FU}=\mathrm{DUF}^{*} \mathrm{TUD}
$$

Vale observar que a determinação da demanda de energia elétrica que deveria ser contratada apenas para o SAA (DC) caso fosse unidade consumidora de energia elétrica independente, foi baseada na instrução técnico-administrativa da Ampla (2009) em função da potência ativa dos CMBs. Os valores de Imposto Sobre Circulação de Mercadorias e Serviços (ICMS) e de desconto (desc) foram consultados na fatura da unidade consumidora de energia elétrica do campus, na qual o SAA está inserido.

Além disso, foram calculados os valores de Custo Médio de Energia Elétrica (CME, em R $\$ / k W h$ ) e de Custo Médio de Energia Elétrica por Metro Cúbico de Água (CMA, Em R $\$ / \mathrm{m}^{3}$ ) do SAA do campus. O CMA foi calculado para as Linhas 1 e 2 levando 
em consideração o consumo agregado de energia elétrica tanto para o horário de ponta como para o horário fora de ponta para ser realizada a comparação dos custos entre os dois horários.

Com os resultados obtidos, foi possível analisar o impacto da operação das EEAs do SAA na despesa de energia elétrica do campus. Além disso, foi estimado o valor da despesa de energia elétrica caso o bombeamento de água que ocorreu no horário de ponta do setor elétrico fosse deslocado para o horário fora de ponta.

\section{RESULTADOS}

No monitoramento, foi verificado que os volumes de água bombeados pelas EEAB, EEAT 1, EEAT 2 e EEAT 3 nos períodos da madrugada ( $0 \mathrm{~h}-6 \mathrm{~h})$, da manhã (6h - 12h), da tarde (12h - 18h) e da noite $(18 \mathrm{~h}-24)$ tiveram variação máxima de $141 \mathrm{~m}^{3}$, $69 \mathrm{~m}^{3}, 136 \mathrm{n}^{3}$ e $37 \mathrm{~m}^{3}$, respectivamente. A maior variação percentual foi de $39,2 \%$ na EEAT 2 e a menor de $7,8 \%$ na EEAT 3. Essas informações indicam que os volumes de água produzidos e encaminhados aos setores de distribuição não tiveram grande variação nos referidos períodos do dia (Tabela 2).

Tabela 2 - Volume de água bombeado por períodos do dia

\begin{tabular}{|c|c|c|c|c|c|}
\hline \multirow{2}{*}{$\begin{array}{c}\text { Unidade de } \\
\text { bombeamento }\end{array}$} & \multicolumn{5}{|c|}{ Volume bombeado de água por período do dia $\mathbf{( m}^{\mathbf{3}} \mathbf{)}$} \\
\hline EEAB & $\mathbf{0 h - 6 h}$ & $\mathbf{6 h - 1 2 h}$ & $\mathbf{1 2 h}-\mathbf{1 8 h}$ & $\mathbf{1 8 h}-\mathbf{~} \mathbf{h}$ & Total \\
\hline EEAT 1 & 929 & 941 & 1.064 & 1.070 & 4.004 \\
\hline EEAT 2 & 266 & 322 & 335 & 291 & 1.214 \\
\hline EEAT 3 & 350 & 380 & 483 & 347 & 1.560 \\
\hline
\end{tabular}

Essa semelhança de valores de volumes bombeados entre os períodos avaliados não era esperada em virtude da ausência da população que utiliza as instalações da universidade entre $21 \mathrm{~h}$ e $7 \mathrm{~h}$. No entanto, esse comportamento pode ser explicado pela presença de laboratórios que demandem água durante a noite, por existência de exportação de água, pela possibilidade de seu uso clandestino, pelo extravasamento das unidades de reservação, pela retrolavagem dos filtros da ETA realizada em períodos noturnos e por perdas físicas nas unidades do SAA, principalmente na rede de abastecimento de água.

Em pesquisa realizada por Rego et al. (2014), foi estabelecido o valor de consumo per capita no mesmo campus universitário estudado na presente pesquisa, igual a 50,08 l/hab.d. Dessa forma, o volume de água bruta captada pela EEAB no período das Oh às $6 \mathrm{~h}\left(929 \mathrm{~m}^{3}\right)$ seria suficiente para atender a 18.550 usuários das instalações da universidade.
Além disso, ainda na pesquisa de Rego et al. (2014), foi identificado o número de pessoas que fazem uso das instalações apenas do setor Básico igual a 11.962 hab que demandam diariamente $599,06 \mathrm{~m}^{3}$ de água. No entanto, na presente pesquisa foi identificado que a EEAT 3, responsável por bombear água para o reservatório elevado do setor Básico, bombeou $1.429 \mathrm{~m}^{3}$ no dia monitorado, valor superior ao dobro da demanda de água identificada. Isso pode ter ocorrido devido a usos especiais de água no SAA como em caso de produção de refeições no restaurante da universidade, em laboratórios que demandem grandes volumes de água, na lavagem de espaços do campus e em perdas de água no SAA. Vale observar que a faixa de erro dos equipamentos de medição é outro fator a ser considerado.

Também foi observado com os dados monitorados que as quatro EEAs funcionaram normalmente no horário de ponta, conforme apresentado na Fig. 4. 
Figura 4 - Volume horário de água bombeado no SAA do campus

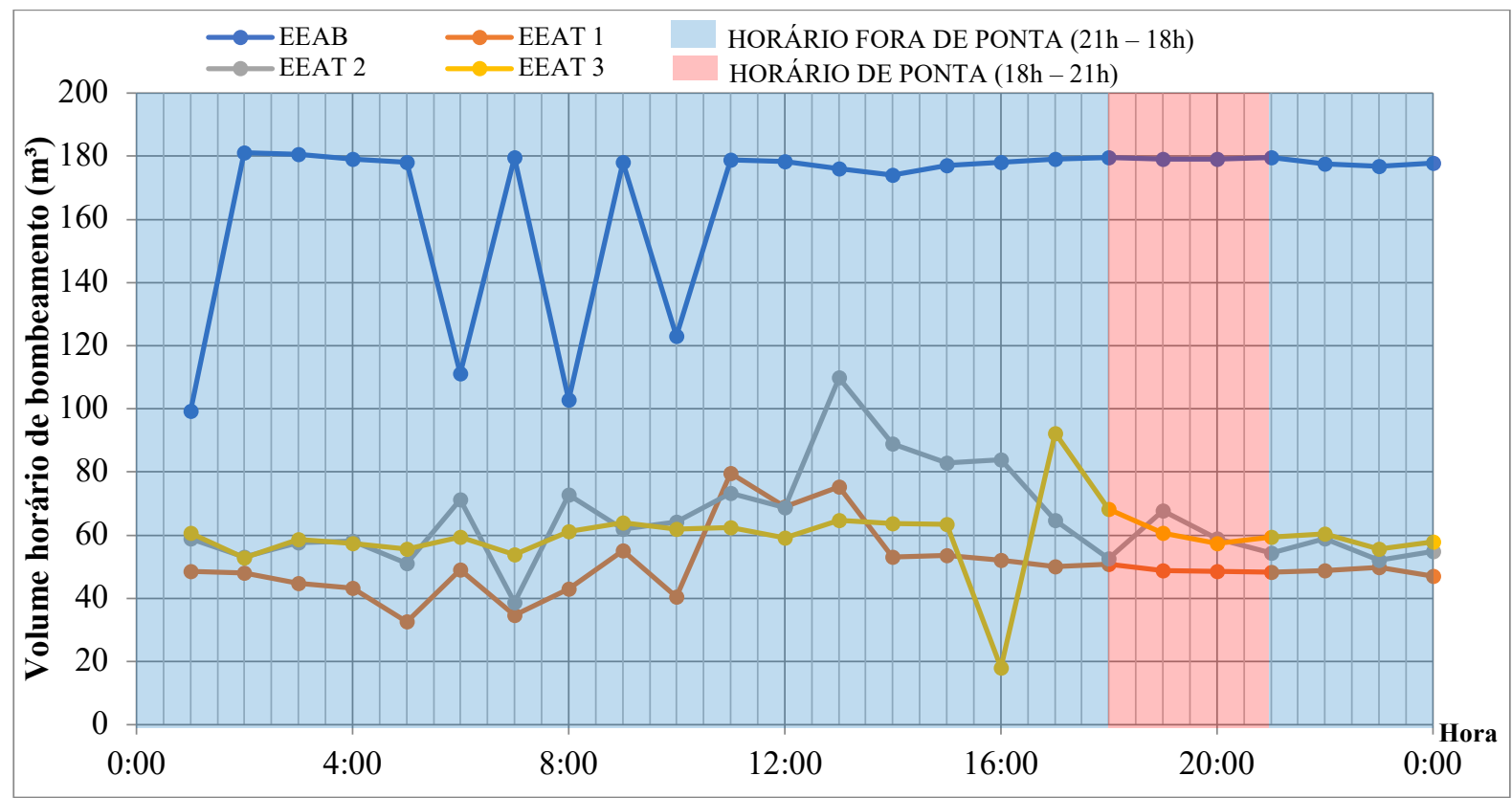

$O$ volume bombeado pelas quatro EEAs foi de $1.043 \mathrm{~m}^{3}$ no horário de ponta e de $7.164 \mathrm{~m}^{3}$ no horário fora de ponta, totalizando $8.206 \mathrm{~m}^{3} \mathrm{de}$ água bombeada por dia no SAA do campus. Durante as três horas do horário de ponta, o bombeamento de água foi de $13,3 \%$ do volume diá- rio bombeado na EEAB, de $12,0 \%$ na EEAT 1, de $11,7 \%$ na EEAT 2 e de $12,5 \%$ na EEAT 3. Vale citar que parte dos valores de volume horário de água bombeado nas quatro EEAs teve proximidade aos valores médios horários, conforme pode ser observado na Fig. 5.

Figura 5 - Diagrama de caixas de volume horário de água bombeado

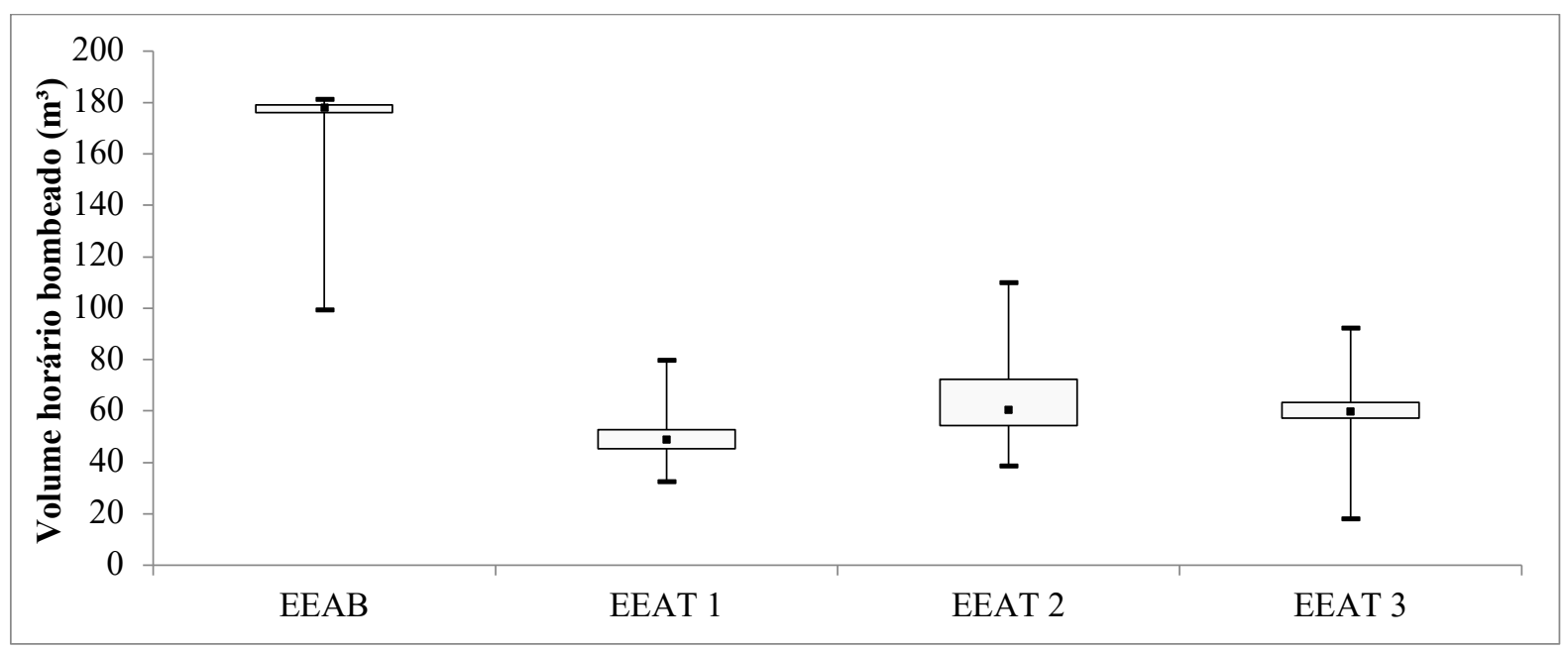


A pequena amplitude nos interquartis do diagrama de caixas significa que $50 \%$ dos valores de volume horário bombeado ao longo do dia tiveram valores próximos, no mínimo durante $12 \mathrm{~h}$ do dia.
Considerando o tempo efetivo de operação das EEAs no dia do monitoramento, o CMB da EEAB foi utilizado por mais de $21 \mathrm{~h}$ (Tabela 3), quando o período esperado era em torno de $14 \mathrm{~h}$, considerando o horário de funcionamento do campus (das $7 \mathrm{~h}$ às $21 \mathrm{~h}$ ).

Tabela 3 - Características da operação dos CMBs das EEAs

\begin{tabular}{|c|c|c|c|c|}
\hline Variável & EEAB & EEAT 1 & EEAT 2 & EEAT 3 \\
\hline Horas de funcionamento por dia (h/dia) & 21,7 & 15,3 & 14,6 & 15,9 \\
\hline Percentual de funcionamento por dia (\%) & $90,4 \%$ & $63,9 \%$ & $60,8 \%$ & $66,2 \%$ \\
\hline Número de acionamento & 5 & 106 & 34 & 92 \\
\hline Período médio de funcionamento (min/acionamento) & 265 & 9 & 26 & 10 \\
\hline
\end{tabular}

Em pesquisa de operação de bombas em SAA, Barbosa et al. (2001) concluíram como valor ótimo seis acionamentos de CMBs por dia. Com isso, apenas na EEAB foi verificado comportamento abaixo do recomendado. Isso pode ser explicado pelo fato de essa EEA não bombear água para uma unidade de reservação de nível controlado, mas diretamente para a ETA. Já os CMBs das demais EEAs tiveram números de acionamento muito superiores ao recomendado.

Os pequenos valores médios de tempo entre a partida e a paralisação dos CMBs da EEAT 1 (9 min), da EEAT 2 ( $26 \mathrm{~min}$ ) e da EEAT 3 ( $10 \mathrm{~min}$ ) confirmam os grandes números de acionamento dos CMBs nas três EEAs, sendo que elas tiveram valores de vazão média horária de bombeamento igual a $50,6 \mathrm{~m}^{3} / \mathrm{h}$, $65,0 \mathrm{~m}^{3} / \mathrm{h}$ e $59,5 \mathrm{~m}^{3} / \mathrm{h}$, respectivamente.

Nesse sentido, considerando os valores médios de vazão de saída iguais aos valores médios de vazão de alimentação dos reservatórios para os quais as EEAT 1, 2 e 3 bombeiam água e os seus volumes totais de reservação (Fig. 2), essas estações elevatórias poderiam ser paralisadas, sem comprometer o abastecimento de água dos setores, durante, em média, 2h22, 2h46 e 2h01 entre acionamentos, respectivamente. Vale observar que o ideal é que as EEAs consigam ser paralisadas durante as três horas do horário de ponta, enquanto a rede de distribuição é alimentada apenas pelo volume de água armazenado nos reservatórios.

Essa informação indica que os reservatórios não estão operando com toda a sua capacidade de reservação, o que pode ser causado pelo posicionamento inadequado dos níveis máximos e mínimos de operação dos reservatórios ou mesmo por problema de funcionamento dos dispositivos controladores de nível, o que torna necessário o maior número de acionamentos das EEAs durante o dia.

Assim, é recomendada a adequação da rotina operacional das EEAs, inclusive com a reavaliação dos volumes úteis de reservação e com a programação dos controles dos níveis máximos e mínimos dos reservatórios, tendo como finalidade aumentar os períodos médios de funcionamento dos CMBs das EEATs 1, 2 e 3 e paralisar o bombeamento nas três horas do horário de ponta do setor elétrico.

Vale ressaltar que a operação irregular de EEAs pode ocasionar aumento na necessidade de manutenção e reduzir a vida útil dos CMBs. Isso porque a partida do motor exige elevadas correntes elétricas para retirar o CMB do estado denominado "rotor bloqueado", ou seja, levar o rotor do estado de inércia até seu regime estabilizado de 
rotação. De acordo com Macintyre (2012), durante a partida, motores elétricos podem utilizar valor até dez vezes maior do que a corrente nominal a plena carga.
$\mathrm{Na}$ pesquisa foram constatados valores semelhantes de consumo médio horário de energia elétrica nos horários de ponta e fora de ponta nas quatro EAAs, conforme apresentado na Tabela 4.

Tabela 4 - Consumo de energia elétrica do SAA nos horários de ponta e fora de ponta

\begin{tabular}{|c|c|c|c|c|c|c|}
\hline \multirow{2}{*}{ EEA } & \multicolumn{4}{|c|}{ Horário de Ponta (18h - 21h) } & \multicolumn{2}{c|}{ Horário Fora de Ponta (21h - 18h) } \\
\cline { 2 - 7 } & $\begin{array}{c}\text { Médio } \\
\text { horário (kWh) }\end{array}$ & Diário (kWh) & Mensal (kWh) & $\begin{array}{c}\text { Médio } \\
\text { horário (kWh) }\end{array}$ & Diário (kWh) & Mensal (kWh) \\
\hline EEAB & 50,9 & 153 & 4.584 & 47,3 & 993 & 29.778 \\
\hline EEAT 1 & 11,0 & 33 & 994 & 11,6 & 243 & 7.287 \\
\hline EEAT 2 & 3,3 & 10 & 301 & 3,6 & 75 & 2.264 \\
\hline EEAT 3 & 7,6 & 23 & 687 & 7,6 & 160 & 4.810 \\
\hline
\end{tabular}

A EEAB apresentou o maior consumo de energia elétrica ( $67,8 \%$ do consumo total do SAA), o que pode ser explicado pela maior potência nominal do seu CMB (60 CV) e pelo grande período de funcionamento $(21,7 \mathrm{~h} / \mathrm{d})$. Considerando as quatro EEAs, foi registrado valor total de 1.690
kWh consumido nas 24 horas do monitoramento, sendo 219 kWh (13\%) consumidos no horário de ponta e $1.471 \mathrm{kWh}(87 \%)$ no horário fora de ponta. Na Fig. 6 são apresentadas as curvas dos consumos horários de energia elétrica das EEAs.

Figura 6 - Valores monitorados de consumo horário de energia elétrica nas EEAs

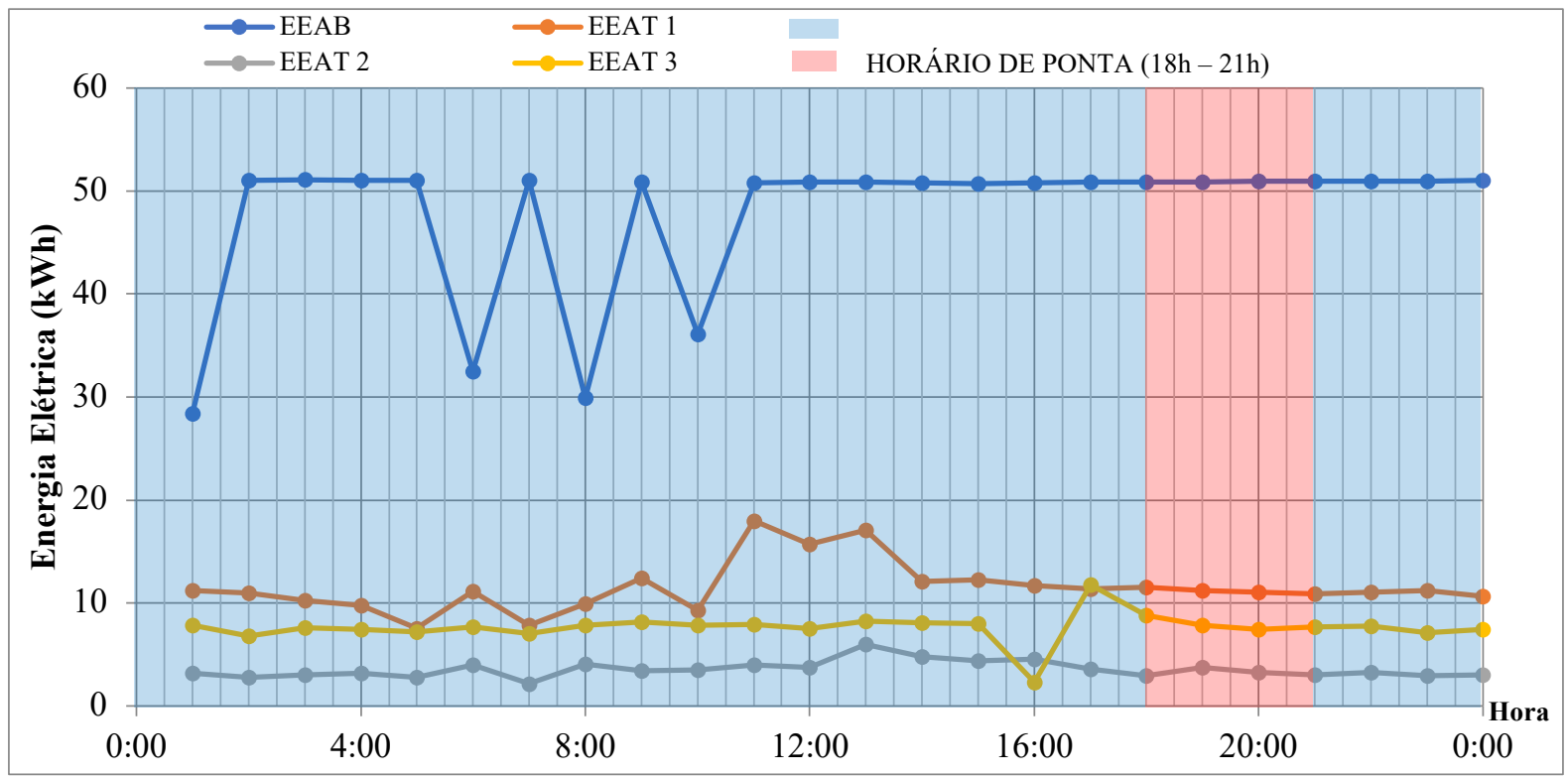

Os valores médios dos fatores de potência monitorados nos CMBs foram de 0,79 na EEAB, de 0,80 na EEAT 1 , de 0,70 na EEAT 2 e de 0,66 na EEAT 3. Esses valores foram inferiores ao valor de
0,83 especificado nos equipamentos, o que pode ter ocorrido devido à inadequação da instalação elétrica do SAA do campus e ao desgaste dos motores ocasionado pela operação dos CMBs. 
Vale destacar que a Agência Nacional de Energia Elétrica (ANEEL) estabelece o valor de 0,92 como limite mínimo para fatores de potência de instalações elétricas. Com isso, o SAA do campus da UFPA está sujeito à aplicação de cobranças devido ao consumo de energia elétrica reativa excedente.

Ainda foi verificado que o CEE variou de $0,05 \mathrm{kWh} /$ $\mathrm{m}^{3}$ na EEAT 2 até $0,29 \mathrm{kWh} / \mathrm{m}^{3}$ na EEAB. Contudo, esses valores não podem ser comparados, já que as quatro EEAs apresentam características físicas e operacionais diferentes. Para possibilitar a análise comparativa da eficiência das EEAs, foram calculadas as alturas manométricas, considerando os valores de vazão máxima monitorados das EEAT 1,2 e 3 iguais a $83,16 \mathrm{~m}^{3} / \mathrm{h}, 114,48 \mathrm{~m}^{3} / \mathrm{h}$ e $94,32 \mathrm{~m}^{3} / \mathrm{h}$, respectivamente, para a estimativa dos valores dos CEEN relacionados na Tabela 5 .

Tabela 5 - Informações hidroenergéticas das EEAs

\begin{tabular}{|c|c|c|c|c|}
\hline Informação & EEAB & EEAT 1 & EEAT 2 & EEAT 3 \\
\hline Volume diário bombeado $\left(\mathrm{m}^{3} / \mathrm{d}\right)$ & 4.004 & 1.214 & 1.560 & 1.429 \\
\hline Energia diária consumida $(\mathrm{kWh} / \mathrm{d})$ & 1.145 & 276 & 85 & 183 \\
\hline Altura manométrica $(\mathrm{m})$ & - & 23,72 & 9,6 & 19,9 \\
\hline CEE $\left(\mathrm{kWh} / \mathrm{m}^{3}\right)$ & 0,29 & 0,23 & 0,05 & 0,13 \\
\hline CEEN $\left(\mathrm{kWh} / \mathrm{m}^{3} / 100 \mathrm{~m}\right)$ & - & 0,96 & 0,57 & 0,64 \\
\hline
\end{tabular}

Como o maior valor de CEEN é relacionado com a menor eficiência no bombeamento de água, foi possível verificar que a EEAT $1\left(0,96 \mathrm{kWh} / \mathrm{m}^{3} / 100\right.$ $\mathrm{m})$ teve a pior condição de operação em relação ao consumo de energia elétrica de acordo com esse indicador. Também é oportuno ressaltar que os valores de CEEN das três EEATs foram maiores do que $0,5 \mathrm{kWh} / \mathrm{m}^{3} / 100 \mathrm{~m}$ comentado por Alegre et al. (2006), confirmando a necessidade de meIhoria na eficiência hidroenergética das EEAs do SAA do campus universitário.

Além disso, em função da agregação de energia elétrica ao volume de água bombeado pelas EEAs, o metro cúbico de água distribuído nos setores profissional, saúde e educação física tem agregado os valores de energia elétrica consumida na EEAB e na EEAT 1 (Linha 1), resultando em valor de CEE agregado igual a $0,52 \mathrm{kWh} / \mathrm{m}^{3}$. Da mesma forma, o valor do metro cúbico de água distribuído no setor Básico tem agregada a energia elétrica consumida na EEAB, na EEAT 2 e na EEAT 3 (Linha 2), resultando em valor de CEE agregado igual a $0,47 \mathrm{kWh} / \mathrm{m}^{3}$. Além disso, nas contas de energia elétrica disponibilizadas pela prefeitura do campus, foi verifi- cado que o SAA está integrado à unidade consumidora de energia elétrica de todo o campus universitário, com enquadramento no subgrupo tarifário A4 de tensão de fornecimento entre 2,3 kV e 25 kV e na modalidade tarifária horossazonal verde. Na Tabela 6 são relacionados, para unidades consumidoras com essas características, os valores de tarifação, de acordo com CELPA (2016), praticados pela concessionária de energia elétrica no período da pesquisa.

Tabela 6 - Valores tarifários da modalidade horossazonal verde

\begin{tabular}{|c|c|c|}
\hline \multicolumn{2}{|c|}{ Modalidade tarifária verde (Subgrupo A4 - de $\mathbf{2 , 3} \mathbf{~ k V}$ a $44 \mathbf{k V}$ ) } \\
\hline Demanda & Consumo ponta & $\begin{array}{c}\text { Consumo fora de } \\
\text { ponta }\end{array}$ \\
\hline $\mathrm{TD}(\mathrm{R} \$ / \mathrm{kW})$ & $\mathrm{TC}(\mathrm{R} \$ / \mathrm{kWh})$ & $\mathrm{TC}(\mathrm{R} \$ / \mathrm{kWh})$ \\
\hline $\mathrm{R} \$ 19,43149$ & $\mathrm{R} \$ 2,25626$ & $\mathrm{R} \$ 0,28859$ \\
\hline
\end{tabular}

Fonte: CENTRAIS ELÉTRICAS DO PARÁ (CELPA), 2016.

Com nos valores apresentados na Tabela 6, foi verificado que o valor da tarifa do consumo de energia elétrica no horário de ponta $(2,25 \mathrm{R} \$ / \mathrm{kWh})$ foi cerca de oito vezes maior do que no horário fora de ponta $(0,29 \mathrm{R} \$ / \mathrm{kWh})$, o que justifica a proposta de 
redução do funcionamento dos CMBs do SAA do campus entre $18 \mathrm{~h}$ e $21 \mathrm{~h}$.

O fato de o SAA do campus não ser unidade consumidora de energia elétrica independente impede o seu enquadramento específico na modalidade tarifária mais adequada para a redução da despesa de energia elétrica, pois, para isso, seria necessário alterar o contrato com a concessionária de energia elétrica, revendo os critérios de tarifação praticados em toda a unidade consumidora do campus. Portanto, ainda não é possível relacionar os valores monitorados no SAA com os faturados pela empresa concessionária.

Apesar disso, para identificar o valor de despesa referente ao consumo de energia elétrica no SAA, foi calculado o valor da fatura de energia elétrica equivalente ao consumo de energia nas EEAs do SAA do campus considerando a metodologia sugerida por Gomes (2012). Vale observar que não foi computada a despesa tarifária de demanda de ultrapassagem (FU), pois no monitoramento foi verificado que o maior valor da demanda de energia elétrica ativa medida (91 kW) não ultrapassou o valor de DC de $94 \mathrm{~kW}$ calculado pela metodologia da Ampla (2009).

Ainda foi adotado o valor de $25 \%$ de ICMS identificado nas faturas de energia elétrica, não sendo observado nenhum desconto (desc). Na Tabela 7 , são relacionados os valores dos componentes da fatura energia elétrica (VF), sendo o valor total estimado de despesa de energia elétrica igual a $\mathrm{R} \$ 46.548,00$ por mês.

Tabela 7 - Despesa mensal de energia elétrica estimada das EEAs do SAA

\begin{tabular}{|c|c|c|c|c|c|}
\hline $\begin{array}{c}\text { Consumo de energia } \\
\text { elétrica ativa (FC) }\end{array}$ & $\begin{array}{c}\text { Demanda de energia } \\
\text { elétrica ativa (FD) }\end{array}$ & $\begin{array}{c}\text { Consumo de energia } \\
\text { elétrica reativa (FER) }\end{array}$ & $\begin{array}{c}\text { Demanda de energia } \\
\text { elétrica reativa (FDR) }\end{array}$ & $\begin{array}{c}\text { Valor estimado a ser } \\
\text { faturado (VF) }\end{array}$ \\
\hline $\mathrm{R} \$ 27.552,00$ & $\mathrm{R} \$ 1.827,00$ & $\mathrm{R} \$ 5.235,00$ & $\mathrm{R} \$ 297,40$ & 0,25 & $\mathrm{R} \$ 46.548,00$ \\
\hline
\end{tabular}

Os baixos valores de fator de potência dos motores elétricos dos CMBs ocasionaram os valores de FER e de FDR, que somados resultaram em $11,9 \%$ do valor total da despesa de energia elétrica do campus. Caso o valor do fator potência fosse igual ou superior a 0,92, os valores de FER e FDR seriam nulos, com consequente redução na despesa de energia elétrica.

Além disso, do total de $\mathrm{R} \$ 46.548,00$ de despesa estimada de energia elétrica mensal do SAA do campus universitário, $\mathrm{R} \$ 23.843,00$ (51,2\%) correspondem ao consumo de energia elétrica no horário de ponta e $\mathrm{R} \$ 22.705,00$ (48,8\%) no horário fora de ponta.

O valor médio de consumo de energia elétrica do campus foi de $1.743 .275 \mathrm{kWh} / \mathrm{mês}$ nos meses de junho e julho de 2016. Por sua vez, para SAA foi estimado, com base nos dados monitorados, o valor de $50.705 \mathrm{kWh} / \mathrm{mês}$ de consumo de energia elétrica nas quatro EEAs, o que correspondeu a $2,9 \%$ do consumo total campus universitário. $\mathrm{Na}$ Fig. 7, são apresentados os valores de consumo de energia elétrica nas EEAs do SAA e em toda a unidade consumidora do campus nos horários de ponta e fora de ponta. 
Figura 7 - Consumo de energia elétrica no horário de ponta e fora de ponta

Campus

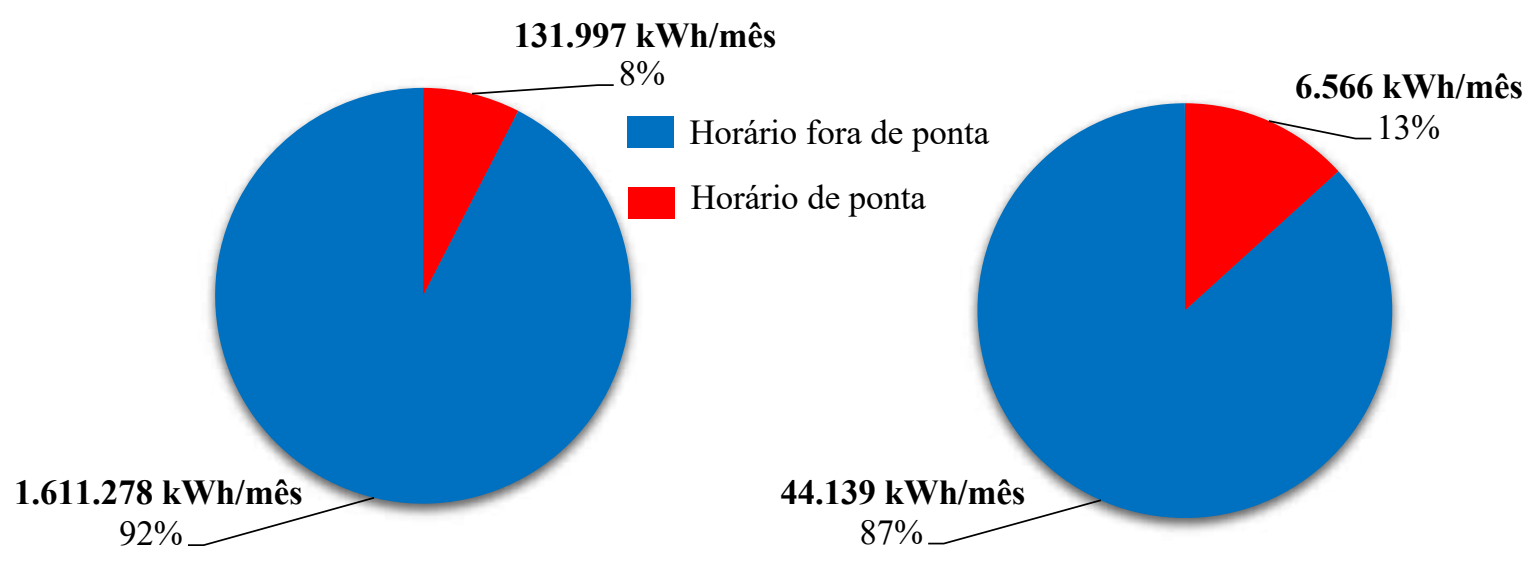

Relacionando os valores obtidos na pesquisa, a despesa estimada de energia elétrica no SAA ( $R$ \$ $46.548,00$ por mês) representou $4,2 \%$ do valor médio da despesa de energia elétrica do campus ( $R \$ 1.115 .623,00$ por mês).

Também foram calculados, para os horários de ponta e fora de ponta, os valores de CME de todo o SAA e de CMA dos setores de distribuição Profissional, Saúde e Educação Física (Linha 1) e do setor de distribuição Básico (Linha 2) em função da energia elétrica agregada ao volume de água distribuído, conforme pode ser observado na Tabela 8.

Tabela 8 - Valores de CME e de CMA

\begin{tabular}{|c|c|c|c|}
\hline Período & $\begin{array}{c}\text { CME } \\
\text { (R\$/kWh) }\end{array}$ & \multicolumn{2}{|c|}{ CMA (R\$nha 1 } \\
\hline $\begin{array}{c}\text { Horário de } \\
\text { Ponta }\end{array}$ & 3,63 & 1,89 & Linha 2 \\
\hline $\begin{array}{c}\text { Horário Fora de } \\
\text { Ponta }\end{array}$ & 0,51 & 0,27 & 1,71 \\
\hline
\end{tabular}

Os valores apresentados na Tabela 8 evidenciam a vantagem de minimizar o consumo de energia elétrica no horário de ponta. Nesse sentido, foi estimado que caso houvesse total paralisação do bombeamento de água das quatro EEAs do SAA durante o horário de ponta, transferindo o volume de água bombeado nesse período para o horário fora de ponta, o valor de despesa de energia elétrica do SAA passaria a ser de $R \$ 26.064,00$ por mês, o equivalente a $56 \%$ do valor estimado para a atual operação monitorada do SAA.

A paralisação do bombeamento de água do SAA no horário de ponta pode ser conseguida por um conjunto de ações como o aumento do controle operacional do SAA, o combate a perdas de água e a adequação dos níveis e dos volumes de reservação à demanda atual do SAA.

\section{CONCLUSÃO}

As quatro EEAs pesquisadas não apresentaram variações expressivas no volume horário de água bombeado, tendo valores semelhantes nos períodos com ( $7 \mathrm{~h}$ às $21 \mathrm{~h}$ ) e sem ( $21 \mathrm{~h}$ às $7 \mathrm{~h}$ ) aula no campus. Esse comportamento não era esperado por não haver população utilizando as instalações do compus após as $21 \mathrm{~h}$, o que indica a possibilidade de ocorrência de consumos especiais 
de água no campus durante o período noturno, como em laboratórios, de perdas significativas de água no SAA e de uso clandestino de água em áreas próximas do campus.

Também foi constatado o elevado número de acionamento e os curtos períodos de operação em três das quatro EEAs, evidenciando que a operação dos reservatórios não utilizou toda a capacidade de armazenamento de água, possivelmente em decorrência de problemas na instalação ou no funcionamento dos sensores para controle do nível de água nos reservatórios.

$\mathrm{Na}$ avaliação dos indicadores de desempenho hidroenergético, foi constatado que as EEATs 1, 2 e 3 apresentaram valores de CEEN maiores do que o valor recomendado de $0,5 \mathrm{kWh} / \mathrm{m}^{3} / 100$ $\mathrm{m}$. Nesse sentido, estudos de intervenções nos CMBs e nas instalações hidráulicas das EEAs podem contribuir para a identificação de ações que possibilitem o aumento da eficiência no bombeamento de água do SAA.

Além disso, a elevação dos valores de fator de potência dos CMBs das EEAs para valores iguais ou superiores a 0,92 é uma ação importante a ser considerada para o SAA do campus, podendo representar economia de até $11,9 \%$ do valor total de despesa de energia elétrica do SAA. Outra economia na despesa de energia elétrica do SAA seria possível com o deslocamento do volume de água bombeado no horário de ponta para o horário fora de ponta, podendo reduzir até $44 \%$ da despesa de energia elétrica das EEAs do SAA.

Dessa forma, é necessário o desenvolvimento de atividades técnicas e modificação da rotina operacional das EEAs para a promoção da eficiência hidroenergética e redução do consumo (50.705 $\mathrm{kWh} / \mathrm{mês}$ ) e da despesa ( $\mathrm{R} \$ 46.548,00$ por mês) de energia elétrica no SAA estudado, que atualmente correspondem a $2,9 \%$ e $4,2 \%$ do consumo e da despesa de energia elétrica do campus da UFPA, respectivamente.

\section{CONTRIBUIÇÃO DOS AUTORES}

Conceitualização, FERREIRA, J. F. H., LOPES, R. M. e PEREIRA, J. A. R.; Metodologia, FERREIRA, J. F. H., LOPES, R. M. e PEREIRA, J. A. R.; Investigação, FERREIRA, J. F. H., LOPES, R. M. e PEREIRA, J. A. R.; Redação - Primeira versão, FERREIRA, J. F. H., LOPES, R. M. e PEREIRA, J. A. R.; Redação - Revisão \& Edição, FERREIRA, J. F. H. e PEREIRA, J. A. R.; Recursos, PEREIRA, J. A. R.; Supervisão, PEREIRA, J. A. R.

\section{REFERÊNCIAS}

ALEGRE, H. et al. Performance indicators for water supply services. Manual of Best Practice Series. 2 ed. London: IWA Publishing, 2006.

AMPLA. ITA 001: Cálculo de Demanda para Medição de Cliente em Baixa Tensão. 2009. Disponível em: <http://vksengenharia. com.br/normas/ITA_001.pdf>. Acesso em: 10 dez. 2016.

AZEVEDO NETTO, J. M. Manuel de Hidráulica / José Martiniano de Azevedo Netto, Miguel Fernández y Fernández. ed. 9. São Paulo: Blucher, 2015.

BARBOSA, J. M. S. G. et al. Operação de Bombas em Sistemas De Abastecimento de Água. In: $21^{\circ}$ Congresso Brasileiro de Engenharia Sanitária e Ambiental. João Pessoa - PB. 2001. Anais... Disponível em: <http://www.bvsde.paho.org/bvsaidis/caliagua/ brasil/i-096.pdf>. Acesso em: 10 nov. 2016.

BARRY, J. Watergy: Energy and Water Efficiency in Water Supply and Wastewater Treatment. Washington, D.C.: Allianceto Save Energy. 2007.

BEZERRA, S. T. M.; CHEUNG, P. B Perdas de água: tecnologias de controle. João Pessoa: Editora da UFPB, 2013.

BRANDT, M. et al. Energy efficiency in the water industry, a Global Research Project. Water Practice and Technology. 2011.

BRASIL. Sistema Nacional de Informações sobre Saneamento: Diagnóstico dos Serviços de Água e Esgotos - 2015. Brasília: SNSA/MCIDADES, 2017. Disponível em: <http://www.snis.gov.br/ diagnostico-agua-e-esgotos/diagnostico-ae-2015>. Acesso em: 27 mar. 2017.

CAVALCANTI, C. Sustentabilidade: mantra ou escolha moral? Uma abordagem ecológica-econômica. São Paulo. 2012.

CELPA. Tarifas. 2016. Disponível em: <http://www.celpa.com.br/ display/499f676e-b44a-4039-97ab-9e91e38f296e>. Acesso em: 10 nov. 2016.

ENVIRONMENTAL PROTECTION AGENCY - EPA. Energy Efficiency for Water Utilities. Sustainable Water Infrastructure. 2017. Dis- 
ponível em: <https://www.epa.gov/sustainable-water-infrastructure/energy-efficiency-water-utilities>. Acesso em: 05 jun. 2018.

GOMES, H. P. Sistema de Bombeamento: Eficiência Energética. 2 ed. João Pessoa: Editora Universitária/UFPB, 2012.

GONÇALVES, R. F.; JORDÃO, E. P.; JANUZZI, G. Introdução. In: GONÇALVES, R. F. (Coord.). Uso Racional de Água e Energia - Conservação de água e energia em sistemas prediais e públicos de abastecimento de água: Projeto PROSAB, Edital 5. Rio de Janeiro: Associação Brasileira de Engenharia Sanitária e Ambiental, 2009.

LUZ, E. et al. Economia de Energia no Sistema de Abastecimento de Água: Uma Abordagem Usando Algoritmos Genéticos. Proceeding Series of the Brazilian Society of Applied and Computational Mathematics, v.4, n.1, 2016. Disponível em: <https:// proceedings.sbmac.org.br/sbmac/article/view/1132>. Acesso em: 10 nov. 2016.

MACINTYRE, A. J. Bombas e Instalações de Bombeamento. 2. ed. rev. Rio de Janeiro: Livros Técnicos e Científicos Editora S. A. 2012.

PEREIRA, J. A. R.; CONDURÚ, M. T. Abastecimento de água: informação para eficiência hidroenergética. João Pessoa: Editora Universitária/UFPB, 2014.

PROCEL INFO. PROCEL SANEAR - Eficiência Energética no Saneamento Ambiental. 2006. Disponível em: <http://www.procelinfo. com.br/data/Pages/LUMIS623FE2A5ITEMID6D82CF76DD284E7B8A607F31CB419A79PTBRIE.htm>. Acesso em: 10 nov. 2016.

REGO, A. G. et al. Avaliação da operação de uma estação de bombeamento de água de um setor de distribuição com base no comportamento de grandezas hidráulicas e elétricas. In: DELGADO-GALVÁN, X.; RODRIGUEZ, J. M.; MEDEL, J. O. (Org.). Los servicios de agua y drenaje com una visión integral. Guanajuato, Universidade de Guanajuato. cap.1, p.10-23. 2015. Disponível em: <http://www. di.ugto.mx/images/produccion_academica_2015/Los\%20servicios\%20de\%20agua\%20y\%20drenaje\%20con\%20una\%20visi\%C3\%B3n\%20integral.pdf>. Acesso em: 08 jun. 2018.

REGO, A. G. et al. Estimativa do Consumo Per Capita em Sistemas de Abastecimento de Água de Cidades Universitárias. In: XIII Sim- pósio Ibero-americano de Redes de Água, Esgoto e Drenagem, 2014. Anais...

SANTOS, A. C. P. A. Desenvolvimento de Modelo de Sistema de Informações Geográficas para Avaliação da Eficiência Hidroenergética em Sistema de Abastecimento de Água. 2015. Tese (Doutorado em Engenharia de Recursos Naturais da Amazônia) - Programa de Pós-Graduação em Engenharia de Recursos Naturais da Amazônia, Instituto de Tecnologia, Universidade Federal do Pará, Belém, 2015. Orientação de José Almir Rodrigues Pereira. Disponível em: <http://repositorio.ufpa.br/jspui/handle/2011/7585>. Acesso em: 25 abr. 2018.

SANTOS, A. C. P. A.; PEREIRA, J. A. R. SIG no gerenciamento de SAAS. Revista DAE. mai./ago. 2016. Disponível em: <http://revistadae.com.br/artigos/artigo_edicao_202_n_1641.pdf>. Acesso em: 10 mai. 2018.

STAVENHAGEN, M.; BUURMAN, J.; TORTAJADA, C. Saving water in cities: Assessing policies for residential water demand management in four cities in Europe. Cities. 2018. Disponível em: <https://www.sciencedirect.com/science/article/pii/ S0264275117307655?via\%3Dihub> Acesso em: 18 mai. 2018.

TANG, Y.; ZHENG, G.; ZHANG, S. Optimal control approaches of pumping stations to achieve energy efficiency and load shifting, International Journal of Electrical Power \& Energy Systems. v 55, p.572-580. fev. 2014. Disponível em: <http://www.sciencedirect.com/science/article/pii/S0142061513004407> Acesso em: 07 jun. 2018.

UNIVERSIDADE FEDERAL DO PARÁ - UFPA. Anuário Estatístico 2017: ano base 2016. Pró-Reitoria de Planejamento e Desenvolvimento Institucional. 2017. Disponível em: <http://www. proplan.ufpa.br/images/conteudo/proplan/dinfi/anuario\%20 estatistico/Anuario2017_AB2016.pdf>. Acesso em: 08 jun. 2018.

ZHUAN, X. et al. Efficient operation of the fourth Huaian pumping station in east route of South-to-North Water Diversion Project, International Journal of Electrical Power \& Energy Systems. v.98, p.399-408. jun. 2018. Disponível em: <http://www.sciencedirect.com/science/article/pii/S0142061517314278>. Acesso em: 11 abr. 2018. 